\title{
A CLINICAL CASE OF TRICHOPHYTON MENTHAGROPHYTES AND MICROSPORUM CANIS CO-INFECTION IN A SIBERIAN TIGER (PANTHERA TIGRIS ALTAICA)
}

\author{
G. MIHAYLOV ${ }^{1}$ I. TSACHEV ${ }^{1}$, V. PETROV ${ }^{1}$, P. MARUTSOV ${ }^{1}$,

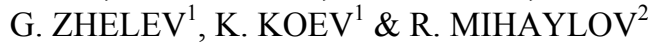

${ }^{1}$ Department of Veterinary Microbiology, Infectious and Parasitic Diseases, Faculty of Veterinary Medicine, Trakia University, Stara Zagora, Bulgaria; ${ }^{2}$ Department of Animal morphology, Physiology and Nutrition, Faculty of Agriculture, Traki a University, Stara Zagora, Bulgaria

\section{Summary}

Mihaylov, G., I. Tsachev, V. Petrov, P. Marutsov, G. Zhelev, K. Koev \& R. Mihaylov, 2016. A clinical case of Trichophyton menthagrophytes and Microsporum canis co-infection in a Siberian tiger (Panthera tigris altaica). Bulg. J. Vet. Med., 19, No 4, 340-345.

A clinical case of co-infection with Trichophyton menthagrophytes and Microsporum canis in a Siberian tiger (Panthera tigris altaica) is described. Clinical and laboratory mycological examinations were carried out. Two dermatophytic species were isolated from hairs, crusts and swab samples from different parts of the cage. A systemic oral therapy with itraconazole (Sporanox, Janssen) at a dose of $10 \mathrm{mg} / \mathrm{kg}$ with food was initiated and body surface was treated with $0.2 \%$ enilconazole solution (Imaverol, Janssen). The skin lesions of the tiger healed after the treatments, but recurred a month later. We recommended a thourough disinfection of the cage area inhabited by tigers and inventory in it. The therapeutic protocol was repeated. Clinical signs disappeared. Information about disease recurrence was obtained.

Key words: dermatophytosis, Microsporum canis, Panthera tigris altaica, treatment, Trichophyton menthagrophytes

\section{INTRODUCTION}

Dermatophytoses are the commonest superficial mycotic infections in animals and humans. In domestic animals, more than 20 dermatophyte species from two genera - Trichophyton and Microsporum, are described (Miller et al., 2013). The main etiological agents are Microsporum canis, Microsporum gypseum and Trichophyton menthagrophytes (Lewis, 1991; Sparkes et al., 1993). Various wild and domestic animal species are natural reservoirs of different members of Microsporum spp. and Trichophyton spp. (Knudtson et al., 1980).

Very rarely, dermatophytoses are caused by two different fungal species 
(Bourdeau et al,. 1982; Bussieras et al., 1982).

Only a few cases of dermatophytosis in captive big cats are reported in the literature. In the present report, we describe a case of generalised dermatophytosis in a Siberian tiger, caused by $M$. canis and $T$. menthagrophytes.

The case refers to two Siberian tiger sibs (brother and sister), 9 months of age, reared together in a cage. The animals were born in Germany and arrived at the Stara Zagora city zoo. Six months ago, the cage they were housed, has been inhabited by wolves, affected by an undiagnosed skin disease. Preventive immunisations and antiparasitic treatments have been performed in Germany. The male tiger exhibited disseminated skin areas with hair loss and crust formations (Fig. 1). The general condition of the animal was not disturbed. Material for mycological examination (hairs and crusts) from affected areas and swab samples $(n=6)$ from different parts of the cage were collected.

The samples for bacteriological and parasitological examinations were collected according to routine procedures. The mycological study in the female tiger (without skin lesions) was done as per the method of McKenzie.

The samples were subjected to native light microscopy for detection of fungal elements (hyphae and arthrospores) after preliminary treatment with $10 \% \mathrm{KOH}$. The cultivation was done on Mycosel agar (Difco) under aerobic conditions, at a temperature of $27^{\circ} \mathrm{C}$ and humidity $30 \%$ over 21 days. The original isolates were subcultivated on Potato-dextrose agar over 21 days, and glass-slide cultures were prepared. The species identification of isolates was conducted on the basis of their macro- and micro morphology features (Rippon, 1988).
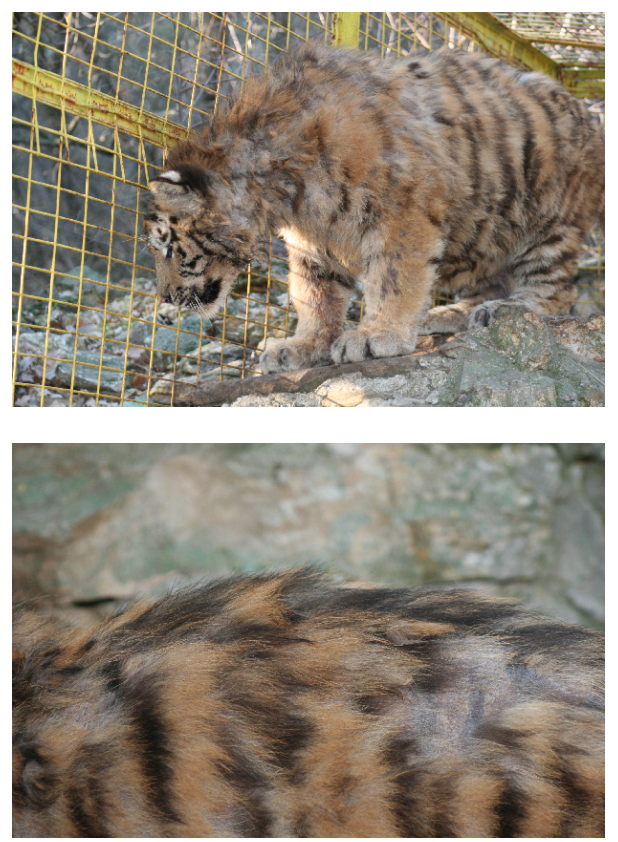

Fig. 1. Skin lesions with hair loss (top) and crusting (down) in the male tiger.

Bacteriological and parasitological studies were done according to routine techniques.

On the basis of mycological analysis results and the clinical signs (generalised dermatophytosis), a systemic oral therapy with itraconazole (Sporanox, Janssen) at a dose of $10 \mathrm{mg} / \mathrm{kg}$ with food was initiated. On the $3^{\text {rd }}$ day of treatment, the tiger refused the medicated food, and then the whole body surface was treated with $0.2 \%$ enilconazole solution (Imaverol, Janssen) at 3-day intervals over 5 weeks.

Disinfection of the cage and the inventory was carried out in the absence of animals with $2 \% \mathrm{NaOH}$ solution at consumption rate of $0.5 \mathrm{~L} / \mathrm{m}^{2}$ and exposure of 1 hour. After that the disinfectant was removed by washing with water.

Native microscopy of hair processed with $10 \% \mathrm{KOH}$ showed arthrospores $2-4$ 
$\mu \mathrm{m}$ in diameter, with ectothrix arrangement. Hyphae were not observed, either around or inside the hair.

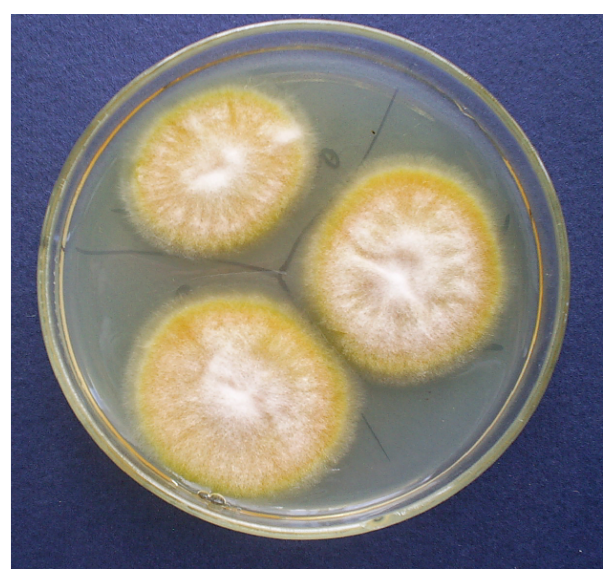

Fig. 2. Colony of M. canis on Mycosel agar (Difco).

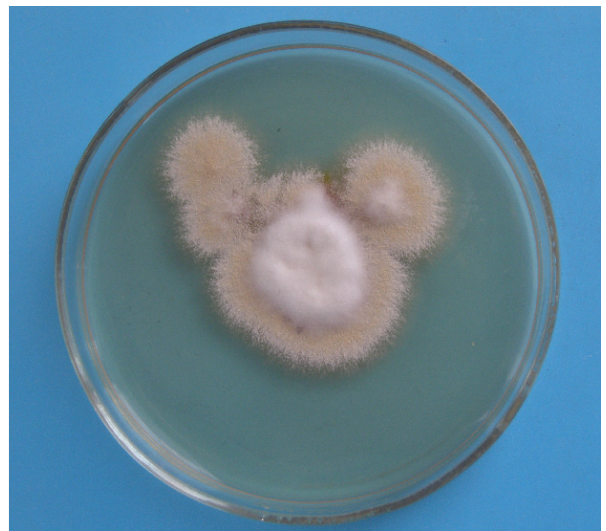

Fig. 3. Colony of $T$. menthagrophytes on Mycosel agar.

The culturing of samples collected from different parts of the body $(n=5)$ showed two morphological types of colonies. In the first type, visible growth was observed as early as the $5^{\text {th }}$ day, the colony surface was white and soft in the centre with yellow periphery, and the reverse side - with bright yellow to orange colors (Fig. 2). The microscopy of this type of colonies on lactophenol cotton blue stained preparations revealed multiple macroconidia, specific for M. canis.

The other study samples became culturally positive by the end of first week presenting colonies with granular offwhite periphery and white centre (Fig. 3). Microscopically, this colony type showed numerous clusters of microconidia, spirals and single cigar-shaped macroconidia. The macro- and micromorphological features of isolates suggested a zoophilic variant of T. menthagrophytes.

All samples collected from different parts of the cage were positive for $M$. canis after culturing. The cultures from the tiger without clinical signs did not reveal any dermatophytes. The bacteriological and parasitological tests were negative for specific pathogens. After 6 treatments with Imaverol at 3-day intervals, the skin lesions of the tiger healed, but recurred a month later.

After disinfection the treatment was repeated following the above-described scheme. During the course of therapy was carried out disinfection once in a week. Three weeks after the second therapeutic course the clinical signs started to decline and hair growth was visible on affected skin areas. Mycological examination of diseased tiger and swabs from the cage made 28 days after the second treatment course were negative for dermatophyte.

We do not have data for a new disease recurrence.

Dermatophytes are microorganisms with cosmopolitan distribution. The infections are well documented in domestic animals, especially dogs and cats (Sparkes et al., 1993; Pinter et al., 2004). In this case we observed typical circular lesions with erythema, hair loss with clear demarcation line, as well as affection of diffuse areas with signs of squamous and pustu- 
lous dermatitis. The frequency of the clinical signs of dermatophytoses depends on the temperature, humidity, rearing conditions and the presence of natural reservoirs of infection (Mancianti et al., 2003). Animals of all ages, breeds and both sexes are susceptible (Cafarchia et al., 2004). Adolescents, especially under one year of age, are affected more frequently. Different predisposing factors as skin microtraumas, other bacterial or parasitic diseases of the skin, immunosuppressive states are triggering factors for clinical manifestations of these infections (Aljabre et al., 1992).

In wild animals, cases of dermatophytosis caused by $M$. canis are reported in tigers (Takatori et al., 1981; Sykes et al., 2007). A case of dermatophytosis in a cougar was reported in Florida in 1999, with two dermatophyte species involved M. gypseum and T. mentagrophytes. M. canis has been isolated also in lions (Panthera leo) (Avram et al., 1958). T. mentagrophytes has been isolated from geoffroy's cats (Leopardus geoffroyi) and jaguar (Panthera onça) (Albano et al., 2013).

For us it was difficult to determine the origin of the source of infection. This may be wolves kept in this cell before or rodents that inhabit the area. In rural regions, rodents are outlined as natural vectors of dermatophytes (Mantovani, 1978). Knudtson et al. (1980) described dermatophytosis cases in red foxes (Vulpes fulva), caused by $T$. mentagrophytes. The analysis of 130 samples from felids in the Sao Paulo zoo, (Bentudo et al., 2006) showed that $1.6 \%$ of healthy lions carried M. gypseum spores. In a retrospective study among red pandas (Ailurus fulgens) performed in the USA, 14 cases of dermatophytosis were established, and the only isolate was M. gypseum (Kearns et al., 1999). In our case, a co-infection with two dermatophytes $-M$. canis and $T$. mentagrophytes was detected. $M$. canis was detected in all samples (swabs) obtained from different parts of the cage. Dermatophyte arthrospores remain viable in the environment for a long time - more than 13 months for M. canis (Dawson \& Noodle, 1968).

Taking into account that the cages where tigers were housed have been previously inhabited by wolves with skin disorders (presumably dermatophytosis), we assume that the contact with surface contaminated with $M$. canis spores was the natural route of this dermatophyte infection. The origin of T. mentagrophytes infection is unknown. For generalised dermatophysoses, a systemic therapy is indicated (Medleau \& White-Weithers, 1992). Itraconazole is a triazole derivative whose action is based on altering the permeability of the cell membrane of fungal cell via inhibited synthesis of ergosterol (Odds, 1993). At low doses, its effect is fungistatic and at high doses - fungicide. Compared to ketoconazole, side effects are less frequently observed.

Enilconazole is an imidazole with fungicide action. It is effective for local therapy in animals and for disinfection of the environment (White-Weithers \& Medleau, 1995). The drug is not approved for use in cats. Different investigations (Hnilica \& Medleau, 2002), and our own observations (Mihajlov et al., 2008) affirmed that it could be used with success to treat dermatophytosis in this species.

Dermatophyte infections raise humoral and cell-mediated immune response. Cellmediated immunity is responsible for the protection of the organism against clinical disease (Svejgaard, 1985). The development of delayed skin hypersensitivity reaction against dermatophyte antigens is related to decrease or disappearance of 
clinical signs, as well as to non-susceptibility to subsequent infections (Jones et al., 1974). The environment, contaminated with fungal elements is a possible route for spread of the infection and reinfections (Dawson \& Noddle, 1968), hence the disinfection with proper substances is an essential element of dermatophyte infections' control (Nesbitt, 1983).

Dermatophytoses in zoo cats are rarely described. The reasons are the small groups in which they are grown (1-2 animals per cage) and rare contacts with other members of the species, which impede transmission by contact. For veterinarians in zoos, dermatophytoses are diseases that do not occur frequently. This complicates and delays the proper diagnosis and adequate treatment. With the description of this clinical case we wanted to remind that dermatophytoses are not only a problem of pet dogs and cats, but also of wild felids and canids.

\section{REFERENCES}

Albano, A. P. N., P. D. S. Nascente, A. T. M. Leite, M. O. Xavier, R. Santin, A. S. Mattei, R. M. P. Humberg, M. A. A. Coimbra, L. F. Minello \& M. C. Meireles, 2013. Isolation of dermatophytes in wild felids from screening centers. Brazilian Journal of Microbiology, 44, 171-174.

Aljabre, S. H. M., M. D. Richardson, E. M. Scott \& G. S. Shankland, 1992. Germination of Trichophyton mentagrophytes on human stratum corneum in vitro. Journal of Medical and Veterinary Mycologia, 30, 145-152.

Avram, A., I. Alteras, M. Carjewski \& M. Iliescu, 1958. Microsporie chez un groupe des lions en captivité. Mycopathology, 9, 288-295.

Bourdeau, P., R. Chermette \& J. Bussieras, 1982. Quelques formes rares de dermatomycoses des carnivores domestiques. 2e cas: dermatite généralisée du chien due à une infection mixte à Microsporum persicolor et à Microsporum gypseum. Point Vétérinaire, 14, 69-72.

Bussieras, J., R. Chermette \& P. Bourdeau, 1982. Quelques formes rares de dermatomycoses des carnivores domestiques. I. Dermatite généralisée du chien, due à une infection mixte par Microsporum canis et par Trichophyton mentagrophytes. Point Vétérinaire, 13, 43-47.

Cafarchia, C., D. Romito, M. Sasanelli, R. Lia, G. Capelli \& D. Otranto, 2004. The epidemiology of canine and feline dermatophytoses in southern Italy. Mycoses, 47, 508-513.

Dawson, C. E. \& B. M. Noodle, 1968. The treatment of Microsporum canis ringworm in a cat colony. Journal of Small Animal Practice, 9, 613-620.

Hnilica, K. A. \& L. Medleau, 2002. Evaluation of topically applied enilconazole for the treatment of dermatophytosis in a Persian cattery. Veterinary Dermatology $\mathbf{1 3}$, 23-28.

Jones, H. E., J. H. Reinhardt \& M. G. Rinaldi, 1974. Acquired immunity to dermatophytes. Archives of Dermatology, 109, 840-848.

Kearns, K. S., C. G. Pollock \& E. C. Ramsay, 1999. Dermatophytosis in red pandas (Ailurus fulgens fulgens): A review of 14 cases. Journal of Zoo and Wildlife Medicine, 30, 561-563.

Knudtson, W. U., C. E. Gates, G. K. Ruth \& L. D. Haley, 1980. Trichophyton mentagrophytes dermatophytosis in wild fox. Journal of Wildlife Diseases, 16, 465-468.

Lewis, D. T., C. S. Foil \& G. Hosgood, 1991. Epidemiology and clinical features of dermatophytosis in dogs and cats at Louisiana State University: 1981-1990. Veterinary Dermatology, 2, 53-58.

Mancianti, F., S. Nardoni, S. Cecchi, M. Corazza \& F.Taccini, 2003. Dermatophytes isolated from symptomatic dogs and cats in Tuscany, Italy during a 15-yearperiod. Mycopathologia, 156, 13-18. 
Mantovani, A., 1978. The role of animals in the epidemiology of the mycoses. Mycopathologia, 65, 61-66.

Medleau, L. \& N. E. White-Weithers, 1992. Treating and preventing the various forms of dermatophytosis. Veterinary Medicine, 87, 1096-1100.

Mihajlov, G., V. Petrov \& G. Zhelev, 2008. Comparative investigation of several protocols for treatment of dermatophytoses in pets. Trakia Journal of Sciences, 6 (Suppl. 1), 102-105.

Miller, W. H., C. E. Griffin, K. L. Campbell \& G. H. Muller 2013. Muller and Kirk's Small Animal Dermatology, $7^{\text {th }}$ edn, Elsevier.

Nesbitt, G. H., 1983. Canine and Feline Dermatology: A Systematic Approach. Lea \& Febiger, Philadelphia.

Odds, F. C., 1993. Itraconazole - a new oral antifungal agent with a very broad spectrum of activity in superficial and systemic mycoses. Journal of Dermatological Science, 5, 65-72.

Pinter, L. \& Z. Stritof, 2004. A retrospective study of Trichophyton mentagrophytes infection in dogs (1970-2002). Veterinarski Arhiv, 74, 251-260.

Rippon, J. W., 1988. Dermatophytosis and dermatomycosis. In: Medical Mycology, $3^{\text {rd }}$ edn, pp. 169-275.

Sparkes, A. H., T. J. Gruffydd-Jones, S. E. Shaw, A. I. Wright \& C. R. Stokes, 1993. Epidemiological and diagnostic features of canine and feline dermatophytosis in the United Kingdom from 1956 to 1991. The Veterinary Record, 133, 57-61.
Sykes, J. M. IV \& E. C. Ramsay, 2007. Attempted treatment of tigers (Panthera tigris) infected with Microsporum canis. Journal of Zoo and Wildlife Medicine 38, 252-257.

Svejgaard, E., 1985. Immunological investigations of dermatophytes and dermatophytosis. In Seminars in Dermatology 4, 201221.

Takatori, K., S. Ichijo \& H. Kurata, 1981. Dermatophytosis of tiger caused by Microsporum canis. Mycopathologia, 73, 105108.

White-Weithers, N. \& L. Medleau, 1995. Evaluation of topical therapies for the treatment of dermatophyte-infected hairs from dogs and cats. Journal of the American Animal Hospital Association, 31, 250-253.

Paper received 10.07.2015; accepted for publication 25.09.2015

\section{Correspondence:}

Vladimir Petrov, DVM, PhD

Department of Veterinary Microbiology, Infectious and Parasitic Diseases,

Faculty of Veterinary Medicine, Trakia University, 6000 Stara Zagora, Bulgaria e-mail: vlado72@abv.bg 